\title{
The Pattern of Dendritic Sprouting and Retraction Induced by Axotomy of Lamprey Central Neurons
}

\author{
Garth F. Hall and Melvin J. Cohen \\ Department of Biology, Yale University, New Haven, Connecticut 06511
}

We have investigated some of the factors controlling the distribution of axonal and dendritic sprouting following axotomy of a subset of Muller giant interneurons (anterior bulbar cells or ABCs) in the hindbrain of the larval sea lamprey (Petromyzon marinus). Sprouts originated from different sites in the cell depending on the distance of the axonal lesion from the soma. When the axon was cut close to the soma (within $500 \mu \mathrm{m}$ ), the dendritic tips sprouted profusely, whereas the proximal axon stump showed few sprouts and frequently disappeared entirely. Axotomy further from the soma $(1000-1400 \mu \mathrm{m})$ resulted in less sprouting from the dendrites and more from the axon stump, with the total amount of dendritic plus axonal sprouting remaining constant. Axotomy at sites distant from the soma (1 cm or more) did not result in dendritic sprouting. No sprouts were ever observed emerging from the soma proper or from the axon stump except at the lesion site. Neuritic sprouts from dendrites and axon were similar in their gross morphology. Sprouts resembled axons rather than dendrites whatever their sites of origin; they followed linear, rostrocaudally oriented paths in the "basal plate" region of the hindbrain. Dendritic and axonal sprouts grew both rostrally and caudally within the brain.

Either "close" or "distant" axotomy resulted in the retraction of the dendritic tree and of both dendritic and axonal sprouts by several months postaxotomy. Reaxotomy close to the soma $30 \mathrm{~d}$ after a distant axotomy accelerated the onset of this evoked dendritic retraction. Reaxotomy close to the soma also induced sprouting significantly sooner than did close axotomy alone.

These results suggest that axotomy close to the soma causes axonal regeneration to be shunted into ectopic locations at the dendritic tips. The emerging sprouts then follow guidance cues appropriate for regenerating ABC axons.

The selective distribution and specific guidance of neurites emerging from a primordial neuron during embryogenesis results in the differentiation of the characteristic form and synaptic connections of the adult neuron. These features in turn largely determine the functional role of the neuron in behavior. Con-

\footnotetext{
Received Dec. 31, 1986; revised Feb. 2, 1988; accepted Feb. 9, 1988.

We thank Ann Poulos for her technical assistance and Haig Keshishian and Sylvie Clausse for their helpful criticism of the manuscript. This work was supported by NIH Spinal Trauma Grant 2P50 NS 10174-14 and NIH Physiology Training Grant GM 15727.

Correspondence should be addressed to Garth F. Hall, Department of Zoology, University of California, Berkeley, CA 94720.

Copyright (C) 1988 Society for Neuroscience $0270-6474 / 88 / 103584-14 \$ 02.00 / 0$
}

sequently, the factors responsible for the generation and maintenance of the characteristic form and connections of a given neuron are of great interest. Although much attention has been paid to the mechanisms by which neurites (usually axons) are guided along characteristic trajectories to their synaptic targets during development or regeneration, less is known about the factors that (1) control the distribution of sprouting sites within a neuron and (2) determine whether neurites become axons or dendrites.

A number of studies indicate that some of the factors determining the nature and distribution of neuronal processes (both during initial development and during regeneration) are intrinsic to the cell. For example, cultured hippocampal neurons can generate recognizable dendrites and axons in the absence of external cues (Bartlett and Banker, 1984). Intrinsic factors are probably also important in determining the distribution of sprouts in some regenerating systems, such as one studied by Schacher and Proshansky (1983), where the presence or absence of an axon stump determines whether isolated Aplysia neurons remain unipolar or become multipolar when cultured following axotomy. Similarly, axotomy of cricket (Roederer and Cohen, 1983) and Helisoma (Murphy and Kater, 1980) neurons in vivo at sites very close to the soma evoke sprouting from the soma or dendrites rather than the axon stump; we have also reported this phenomenon in lamprey central neurons (Hall and Cohen, 1983).

In order to better understand the factors that control the distribution of sprouting within a neuron following injury, we have studied neuritic sprouting induced by axotomy in a subgroup of Muller reticulospinal interneurons in the CNS of the sea lamprey, a primitive vertebrate. This group of neurons (anterior bulbar cells, or ABCs) is a set of 6 large, bilaterally paired cells located on the floor of the IVth ventricle in the hindbrain. Unlike most vertebrate central neurons, $A B C s$ are easily visible in the living animal, highly accessible to surgery, and have stereotyped dendritic morphology (Fishman, 1975; Martin, 1979; Hall and Cohen, 1983). These cells are also known to regenerate their axons across a lesion in the spinal cord where they form synapses (Rovainen, 1976; Selzer, 1978; Wood and Cohen, 1979). In a preliminary study, we found that $\mathrm{ABCs}$ can be induced to sprout vigorously from both axonal and dendritic compartments (Hall and Cohen, 1983). They also exhibit a general retraction of their processes at long intervals postaxotomy (Fishman, 1975), a phenomenon that has also been observed in vertebrate motoneurons (Cerf and Chacko, 1958; Sumner and Watson, 1971). This large repertory of plasticity makes lamprey ABCs especially suitable for studying the factors that regulate neuronal form.

Portions of this work have been published in preliminary form (Hall and Cohen, 1983). 


\section{Materials and Methods}

Surgical procedures. Large larval sea lampreys (Petromyzon marinus) 8 $\mathrm{cm}$ or longer were anesthetized by immersion for several minutes in a $0.13 \%$ aqueous benzocaine solution. Surgery was performed in oxygenated lamprey saline (Wickelgren, 1977) with the animal pinned through the fleshy tissues of the snout and gills onto a Sylgard-lined Petri dish. Lesions were made with a No. 11 scalpel blade. For "distant" axotomy of $\mathrm{ABCs}$ in the spinal cord (1-1.5 cm from the soma), the entire spinal cord was severed with a dorsal incision at the level of the fifth gill. For "close" ( $<500 \mu \mathrm{m}$ from the soma) and "intermediate" (1-1.4 mm from the soma) axotomy in the hindbrain, a dorsal incision through the cartilaginous skull was made at the rostral midbrain. The top of the skull and the choroid plexus were then partially freed with iridectomy scissors and reflected back to expose the floor of the IVth ventricle. A steady flow of saline (Wickelgren, 1977) was directed at the incision throughout the operation to prevent the brain from being obscured by bleeding. The outlines of $\mathrm{ABC}$ somata could be readily distinguished in the dissecting microscope and were identified by their large size, elliptical outline, and medial position at the level of the VIIIth nerve. "Close" and "intermediate" axotomy could then be accomplished with a hemisection of the hindbrain (see Fig. 1). After lesioning, the choroid and skull flap were replaced. No suturing was required, as coagulating blood from the incision provided an effective seal of the wound. Postoperative lampreys were allowed to recover in lamprey saline for at least $24 \mathrm{hr}$ and were then returned to well water via a graded series of dilutions over the next 3-6 d, where they were maintained until sacrificed.

Morphology. Lampreys were anesthetized as described above and their brains and spinal cords removed and placed in a saline-filled, Sylgard-lined chamber. Intracellular injection of Lucifer yellow (Stewart, 1978 ) into ABC somata was used to study the morphology of both normal and axotomized cells. The tips of thin-walled glass micropipettes were filled with a $5 \%$ aqueous solution of Lucifer yellow and then backfilled with a $5 \mathrm{~mm}$ solution of $\mathrm{LiCl}$. The resulting electrodes had resistances of 15-40 M . Identification and impalement of ABCs was accomplished with visual guidance under a dissecting microscope. Dye was injected using $5 \mathrm{~Hz}$ hypcrpolarizing current pulscs $20-30 \mathrm{nA}$ in amplitude and $100 \mathrm{msec}$ in duration over a period of 2-5 min. Brains were then fixed in $4 \%$ formaldehyde, dehydrated in an ethanol series, and cleared in methyl salicylate. ABCs filled with Lucifer yellow were then examined in whole mount under transmission fluorescence optics and photographed. When cross sections of whole mounts were desired, the brains were returned to $100 \%$ ethanol, cleared in propylene oxide, and embedded in Spurrs medium. Serial sections, $10 \mu \mathrm{m}$ thick, were cut on a microtome using glass knives, mounted on slides, and rephotographed.

Data analysis. Drawings of whole-mounted ABCs were made by projecting slides taken at a series of focal planes onto paper sheets at a fixed distance from the projector lens. The extent of sprouting was then determined by measuring lengths of thin wire solder that had been superimposed on tracings of neurites that were identified as sprouts if they met one of the following criteria: (1) they extended beyond the normal dendritic field, (2) their trajectories were atypical of dendrites, or (3) they had swollen tips. Estimates of "total sprout length" thus consistently underestimated the actual extent of sprouting, as the dorsoventral extent of sprouts was foreshortened by projection onto a planar surface. Sprouts were considered linear if they showed a total lateral excursion of $<20 \mu \mathrm{m}$ in a given $200 \mu \mathrm{m}$ segment of brain (sprouts $<200 \mu \mathrm{m}$ long were not counted). Sprouts were considered rostrocaudally aligned if they were oriented within $45^{\circ}$ of the rostrocaudal axis. Only sprouts meeting both of these standards were called "linear, rostrocaudal" sprouts. Reconstructions of $A B C s$ to give cross-sectional views were prepared from serial thick sections by tracing the projected images of each section on a single paper sheet to produce a composite image.

\section{Results}

\section{Normal morphology}

The gross morphology of 181 intact ABCs injected with Lucifer yellow was identical to that revealed by previous studies using intracellular injections of cobalt acetate (Fishman, 1975), HRP (Wood and Cohen, 1981), and Procion yellow (Martin, 1979) into large, anteriorly located bulbar cells in the lamprey hindbrain (Fig. 2A). The results of all of these studies indicate that

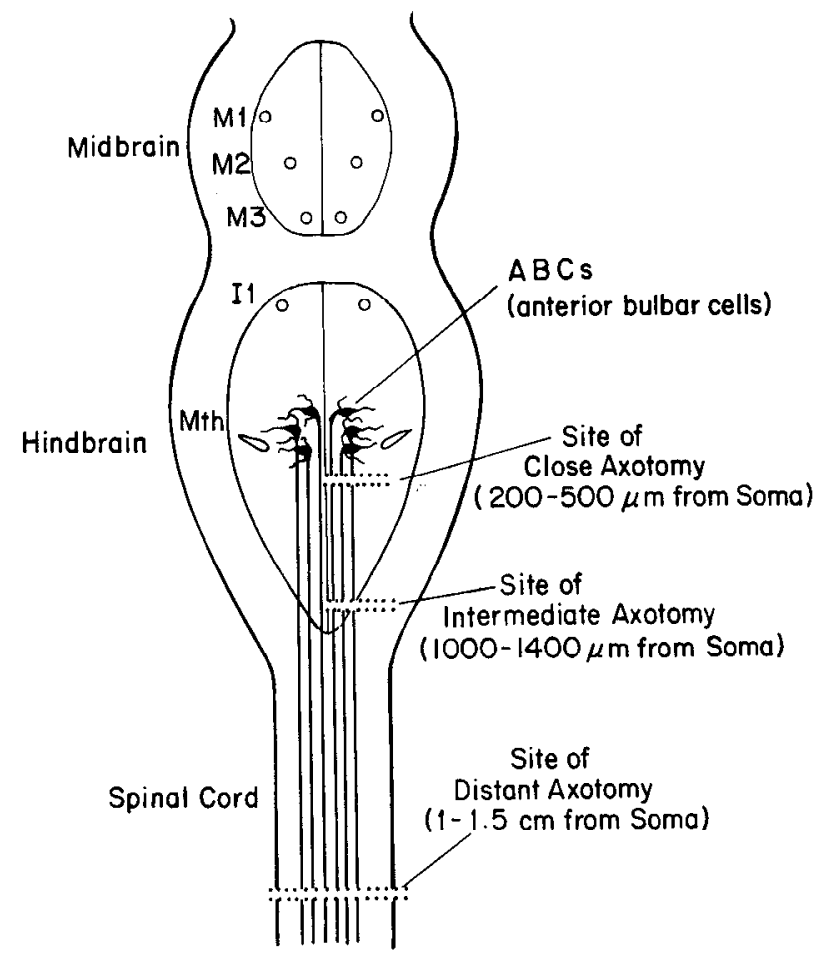

Figure 1. Sites of axotomy in the lamprey CNS. Schematic diagram of the brain and spinal cord of the lamprey (dorsal view) showing the locations of the 3 most anterior pairs of giant bulbar reticulospinal neurons (anterior bulbar cells, or ABCs). The approximate locations of other giant Muller $(M 1-M 3, I I)$ and Mauthner $(M t h)$ cell bodies are also shown. The sites of lesions made in the brain and spinal cord to produce "close," "intermediate," and "distant" axotomy are shown by double-dotted lines. All lesions consisted of transverse cuts through the entire dorsoventral extent of the brain with a No. 11 scalpel blade. In some cases, close and intermediate axotomy were performed bilaterally.

$\mathrm{ABC}$ morphology is highly stereotyped. $\mathrm{ABC}$ somata are large and ellipsoidal, measuring $60-100 \mu \mathrm{m}$ along their major axis and are located immediately beneath the ependymal cell layer lining the floor of the fourth ventricle. The axons are straight, unbranched processes extending caudally and ipsilaterally from the soma along the midline in the ventral tracts for most of the length of the spinal cord. $\mathrm{ABC}$ dendrites are divided into 2 major domains, one extending laterally from the soma and the other medially (Fig. $2 B$ ). The lateral domain consists of 1 or 2 thick, profusely branched primary dendrites which extend from the lateral aspect of the soma for approximately $150 \mu \mathrm{m}$ before turning ventromedially. The medial domain is smaller and more variable than the lateral arborization, consisting of one or a few primary dendrites extending ventromedially from the soma along the wall of the medial sulcus for $50-100 \mu \mathrm{m}$. Most variations in this plan occur only in the number and trajectories of higherorder dendrites. The only feature that varies significantly from cell to cell is the overall rostrocaudal extent of the dendritic tree, which ranges between 150 to $200 \mu \mathrm{m}$ in most cells, but can occasionally reach up to $400 \mu \mathrm{m}$ (see, for example, the control cell in Fig. $5 B$ ). The shape and extent of the dendritic tree is nonetheless well defined in that most $A B C$ dendrites are restricted to narrowly defined branching patterns. Consequently, the experimentally induced dendritic changes described here and in the accompanying paper (Hall and Cohen, 1988) could be readily distinguished from the minor variations seen in normal dendritic morphology. 

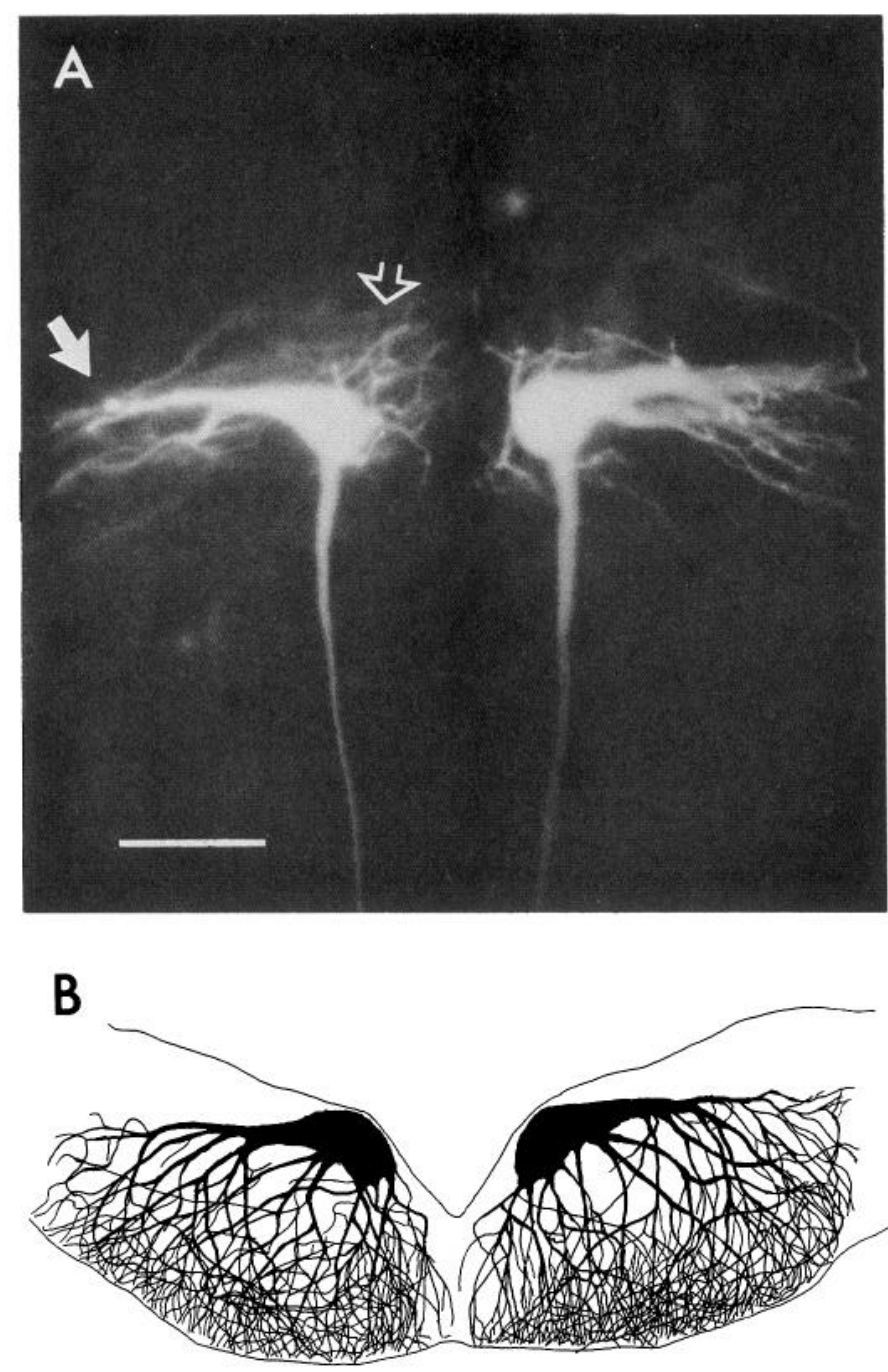

Figure 2. Normal ABC morphology. A, Dorsal view of a pair of ABCs that have been injected with Lucifer yellow showing the normal morphology of $\mathrm{ABC}$ dendrites and the proximal region of the axon. This plane of focus shows the characteristic large dendrite extending laterally from the soma (solid arrow). The medial dendritic domain appears here as a group of primary dendrites emerging from the ventromedial aspect of the soma (hollow arrow). Most other dendrites extend ventrally or ventrolaterally from either the soma or the lateral dendrite out of the plane of view. The dendritic tree is relatively flattened in the rostrocaudal dimension, with most dendrites remaining within $100 \mu \mathrm{m}$ of the plane of the soma. By contrast, the axon is unbranched and linear, extending caudally for nearly the entire length of the spinal cord. Top of photo is rostral. $B$, Cross-sectional reconstruction of the same cells shown in $A$. Note that $\mathrm{ABC}$ dendrites taper steadily from base to tip without varicosities and branch at regular intervals, with the finest dendrites being evenly distributed along the ventral margin of the brain. $\mathrm{ABC}$ dendrites do not cross the central sulcus. Scale bar, $100 \mu \mathrm{m}$.

\section{Dendritic sprouting following close axotomy}

The first dendritic change observed following close axotomy was the appearance of knoblike swellings at the tips of some dendrites in cells between 5 and $15 \mathrm{~d}$ postaxotomy (Fig. $3 A$, arrow). These swellings ranged from slight expansions to large structures of up to $20 \mu \mathrm{m}$ in diameter and occurred within the normal confines of the dendritic tree. Swellings were only found at dendritic tips; dendritic shafts never had swellings or varicosities at any time following close axotomy. The proportion of cells bearing swollen dendritic tips increased with time following axotomy, with $38 \%$ of 26 cells showing some swollen tips between 5 and 10 d postaxotomy and $68 \%$ of 25 cells having them by $10-15 \mathrm{~d}$.

ABCs examined $15 \mathrm{~d}$ or more after close axotomy possessed neuritic sprouts extending beyond the limits of the dendritic field, as well as swollen dendritic tips. The sprout tips were also frequently swollen, suggesting that swollen dendritic tips may be sprouts in an early stage of development, before they have grown sufficiently to be distinguishable from dendrites. Identification of sprouts was simplified by the abrupt change seen in most sprout trajectories at their point of emergence from the dendritic tree (Fig. $3 B$ ). Sprouts from the dendrites increased steadily in both length and number until 80-100 d postaxotomy, by which time they often extended throughout the ipsilateral hindbrain and into the midbrain and spinal cord (Fig. $3 \mathrm{C}$ ). Some individual sprouts reached lengths of $3 \mathrm{~mm}$ or more.

Close axotomy of ABCs was usually accomplished by hemisection of the hindbrain, with one side left intact as a control. No sprouting was ever observed in the 127 control cells examined. In a few instances, the lesion extended across the midline, axotomizing some contralateral cells and leaving others with intact axons located immediately adjacent to the lesion (Fig. $3 B$ ). We also found animals in which the hemisection of the hindbrain was incomplete, sparing a small region near the midline on the lesioned side that contained one or more ipsilateral $\mathrm{ABC}$ axons. In all of these cases, dendritic sprouting was always limited to axotomized cells. This suggests that massive lesions of immediately adjacent areas of the brain cannot substitute for the direct effects of axotomy, and that axotomy is required to evoke dendritic sprouting from $\mathrm{ABCs}$.

The short axon stump remaining attached to the soma after close axotomy either gave rise to 1 or 2 sprouts or disappeared entirely. Dendritic sprouting always greatly exceeded axonal sprouting, even though sprouts emerging from the periaxonal region of those cells lacking an obvious axon stump were always counted as "axonal" sprouts (Table 1).

\section{Control of sprout distribution by the site of axotomy}

Axotomy of ABCs at sites further than $500 \mu \mathrm{m}$ from the soma resulted in a different distribution of sprouts from that produced by close axotomy. "Intermediate" axotomy $(1000-1400 \mu \mathrm{m}$ from the somata) induced significantly less dendritic and more axonal sprouting than did close axotomy by $50 \mathrm{~d}$ postlesion (Fig. 4, Table 1). The total amount of sprouting was approximately the same following close and intermediate axotomy (Table 1), suggesting that there is a redistribution of sprouting from the dendrites to the axon as the axotomy site is moved further from the soma.

The different distributions of sprouting between the dendrites and axon caused by close and intermediate axotomy were due to differences in the number of sprouts originating from each of these locations rather than in the lengths of individual sprouts. With intermediate axotomy, fewer sprouts originated from the dendrites than after close axotomy. However, the mean lengths of individual dendritic sprouts were the same following close and intermediate axotomy. This same pattern held true for differences in the amount of axonal sprouting evoked by close and intermediate axotomy (Table 1). Thus, changing the axotomy site appears to redistribute a fixed number of growth sites within the cell without systematically affecting the rate of growth from each site. 

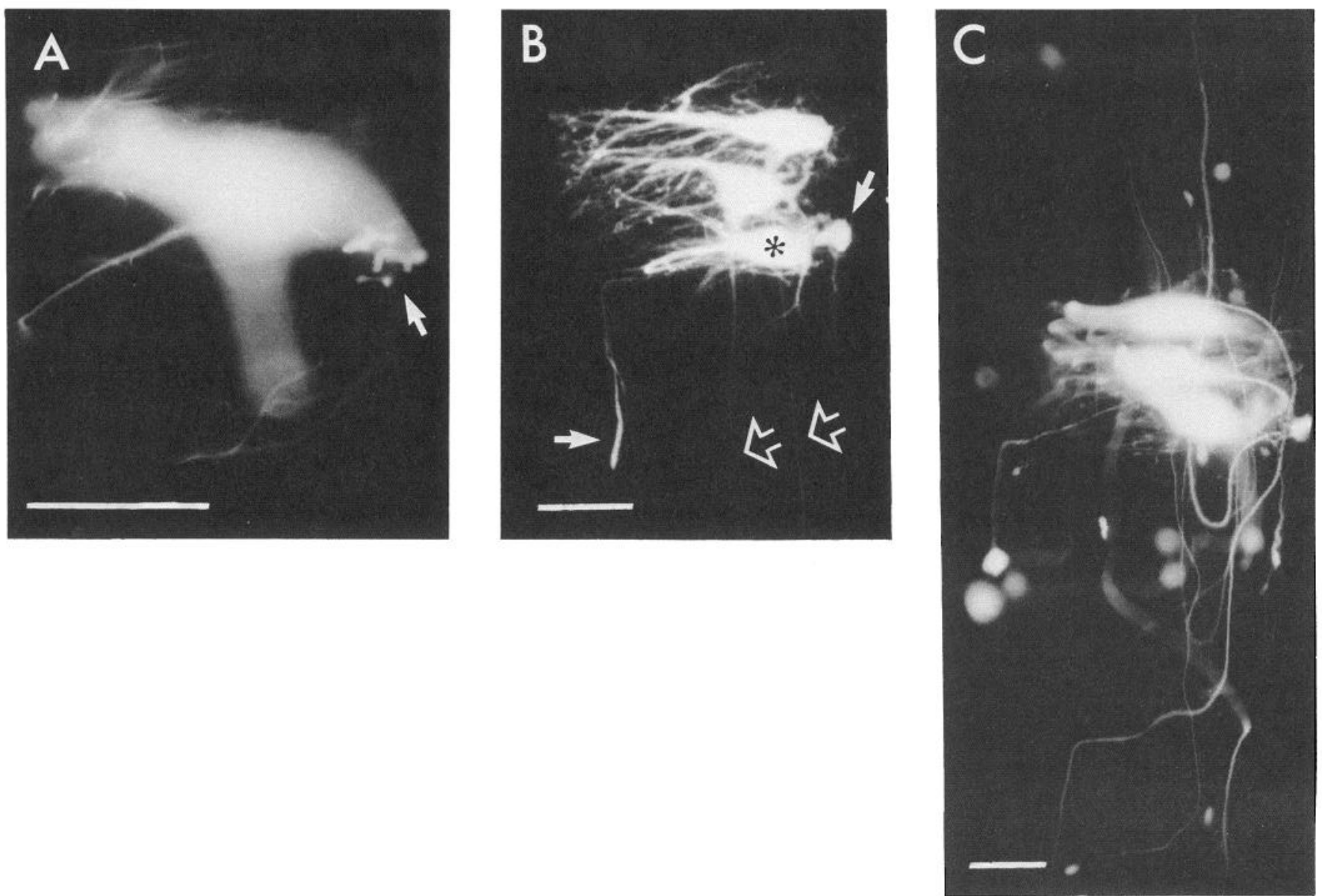

Figure 3. ABCs subjected to close axotomy in the hindbrain and filled with Lucifer yellow at successively later times postlesion. $A$, ABC showing swollen dendritic tips (arrow) $14 \mathrm{~d}$ following close axotomy. These are the first changes seen in ABC dendritic morphology after close axotomy and probably represent the onset of dendritic sprouting. $B$, ABCs $27 \mathrm{~d}$ after close axotomy of the caudalmost cell (asterisk). In this animal, the main lesion was on the contralateral side of brain (not shown). The lesion crossed the midline to cut the axon of the caudalmost cell, leaving the axons of the other cells intact (hollow arrows). The intact cells do not sprout, whereas 2 sprouts can be seen emerging from the dendrites of the axotomized cell (solid arrows). One of these sprouts now extends beyond the normal dendritic field on a trajectory atypical of $\mathrm{ABC}$ dendrites. $C$, ABCs showing extensive dendritic sprouting $82 \mathrm{~d}$ after close axotomy. Note large swellings on many sprout tips. Scale bars $(A-C), 100 \mu \mathrm{m}$.

Almost all axonal sprouts evoked by intermediate axotomy ( 289 of a total of 290 sprouts) originated from within $100 \mu \mathrm{m}$ of the end of the proximal axon stump (Figs. $4 B, 5 B$ ). Only one sprout emerged from the stump at a site distant from the lesion. No sprouts originated from the dendrite-free dorsal aspect of the soma. Axonal sprouts often emerged from the end of the stump as one short, thick sprout that then split into several narrower branches, each of which individually resembled dendritic sprouts.

Distant axotomy of $\mathrm{ABCs}$ in the spinal cord at a point 1 to $2 \mathrm{~cm}$ from the soma induced only one dendritic sprout in 21 cells examined at $50 \mathrm{~d}$ postaxotomy. No sprouting was ever seen from the shaft of the axon near the soma. The morphology of the cut end of the axon was not examined with Lucifer yellow, as insufficient amounts of the dye were transported there after injection at the soma to be visualized by the fluorescence methods available. Other studies have shown, however, that Muller cell axons (including ABCs) sprout vigorously after axotomy in the gill region (Wood and Cohen, 1979, 1981) and that the gross morphology of these sprouts is similar to that of axonal and dendritic sprouts described in this study.

\section{Trajectories and morphology of sprouts induced by axotomy}

The trajectories and gross morphology of dendritic sprouts evoked by close and intermediate axotomy were similar to those of axonal sprouts evoked by intermediate axotomy (Fig. 5). Sprouts originating from both dendritic and axonal locations tended to follow linear, rostrocaudally oriented paths through the brain, rarely crossing the midline. An exception to this pattern was found among sprouts growing near the site of axotomy. These frequently followed tortuous or laterally oriented pathways (Table 2). Sprouts that grew through the lesion into uninjured areas of the brain thus followed tortuous pathways near the lesion and then exhibited linear, axial growth elsewhere. Linear, axially oriented sprouts usually maintained a constant depth within the brain, frequently growing near the ventral margin (Fig. 6).

The tips of sprouts evoked by close and intermediate axotomy displayed a wide variety of forms ranging from (1) tapered endings to (2) elongated, spindle-shaped swellings to (3) spherical and amorphous blebs of various sizes. There was no obvious correlation between the site of sprout origin and sprout tip mor- 


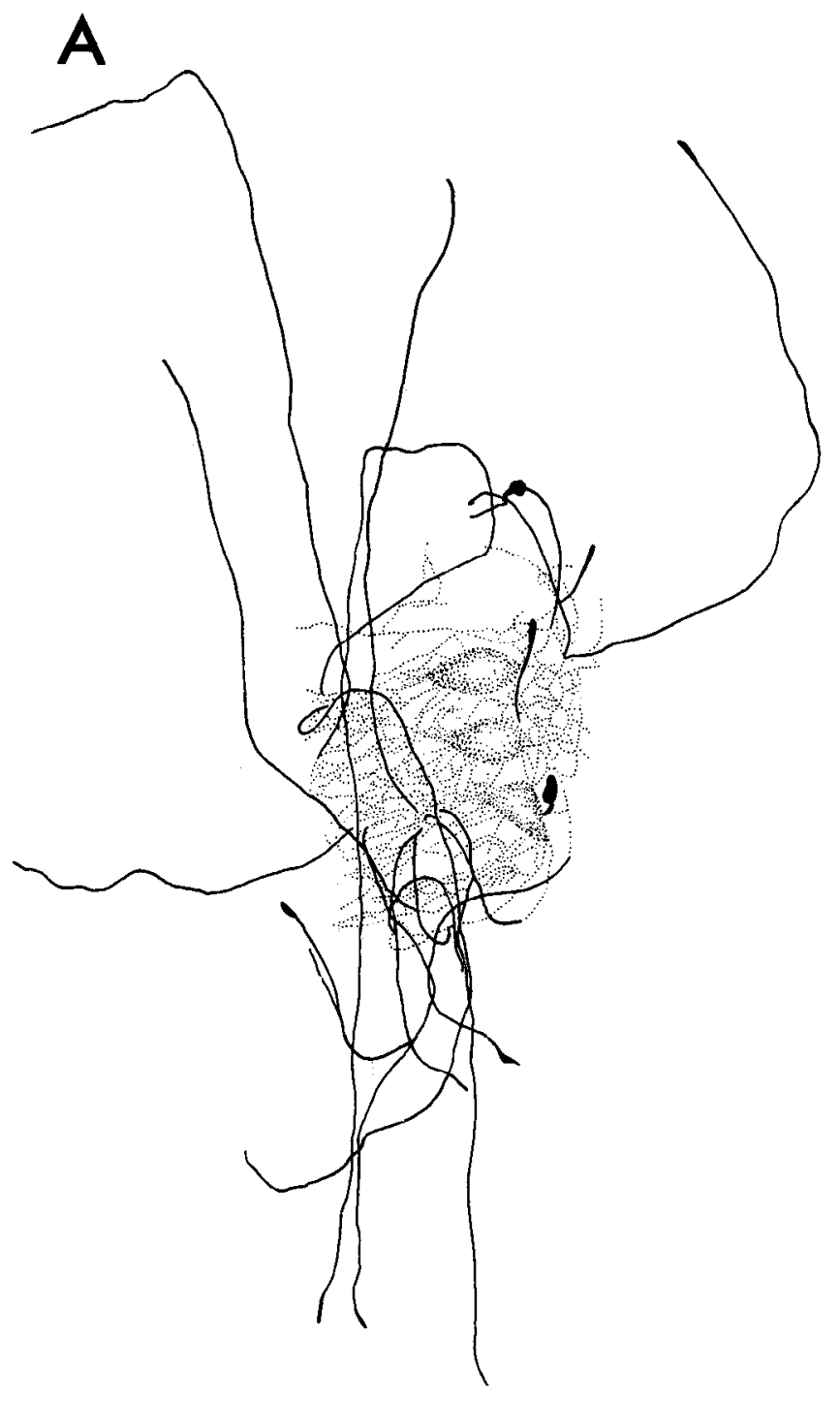

B

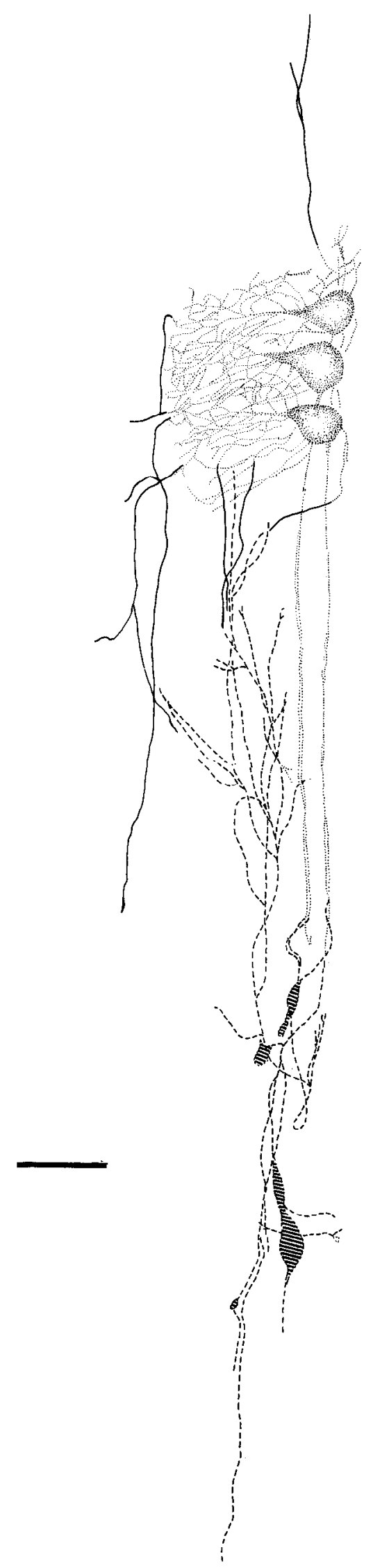




\begin{tabular}{|c|c|c|c|}
\hline Parameter & $\begin{array}{l}\text { Axonal } \\
\text { sprouts }\end{array}$ & $\begin{array}{l}\text { Den- } \\
\text { dritic } \\
\text { sprouts }\end{array}$ & $\begin{array}{l}\text { Total } \\
\text { sprouts }\end{array}$ \\
\hline \multicolumn{4}{|l|}{ Close axotomy $(n=21)$} \\
\hline Summed sprout length/cell $(\mu \mathrm{m})$ & 463 & 3401 & 3864 \\
\hline Mean sprout length $(\mu \mathrm{m})$ & 272 & 243 & 246 \\
\hline Mean sprout number/cell & 1.7 & 14.0 & 15.7 \\
\hline \multicolumn{4}{|l|}{ Intermediate axotomy $(n=27)$} \\
\hline Summed sprout length/cell $(\mu \mathrm{m})$ & 2798 & 1108 & 3906 \\
\hline Mean sprout length $(\mu \mathrm{m})$ & 239 & 258 & 244 \\
\hline Mean sprout number per cell & 11.7 & 4.3 & 16.0 \\
\hline
\end{tabular}

Changing the site of axotomy alters the distribution of sprouting between axon and dendrites at $50 \mathrm{~d}$ postaxotomy by changing the amount of sprouting and the number of sprouts emerging from each compartment $(p<0.01$, Mann-Whitney $U$ test). The total amount of sprouting (as measured by the summed sprout lengths of all dendritic and axonal sprouts) and the mean length of both dendritic and axonal sprouts (determined by dividing the total number of sprout tips into the summed sprout length) do not change. The value for axonal sprouts following close axotomy includes all periaxonal sprouts that could not be traced to specific dendrites. $n$ refers to the number of cells examined.

phology; sprouts of both dendritic and axonal origin gave rise to the entire spectrum of tip shapes listed above. A correlation was found, however, between sprout trajectory and tip morphology. Spindle-shaped tip expansions constituted $82 \%$ of the swollen tips seen on linear, axially oriented sprouts, whereas only $22 \%$ of laterally oriented, nonlinear sprouts had such tips.

Although both axonal and dendritic sprouts induced by axotomy tended to grow either rostrally or caudally in unlesioned areas of the brain, they exhibited no preference for caudal growth over rostral growth or vice versa. The direction of recent sprout growth (represented by the orientation of the terminal $100 \mu \mathrm{m}$ of each sprout) also reflected a lack of preference between rostral and caudal growth (Table 3). Sprouts did not appear to reorient themselves after their initial outgrowth, as the direction of recent sprout growth did not change systematically with time after close axotomy (Table 3). Furthermore, there did not appear to be a significant bias in favor of caudal growth which was masked by the disruption of sprout trajectories at the axotomy lesion site. This is indicated by the observation that dendritic sprouts resulting from intermediate axotomy (which never reached the lesion) were oriented rostrally ( 37 sprouts) as often as they were caudally (40 sprouts).

\section{Dendritic retraction after long periods post axotomy}

The main response of ABCs to axotomy during the first 2-3 months postlesion consisted of neuritic sprouting from the axon stump and/or the dendritic tree, depending on the site of axotomy. After this time, however, other changes (henceforth collectively called "retraction") appeared in both dendrites and the sprouts originating from them. The occurrence of dendritic retraction did not vary with the site of axotomy (Fig. 7).

Dendritic retraction is characterized by a marked narrowing
Table 2. Influence of sprout origin and proximity to the lesion on sprout trajectory

\begin{tabular}{lcccc} 
Group & $\begin{array}{l}\text { Den- } \\
\text { dritic } \\
\text { sprouts }\end{array}$ & $\begin{array}{c}\text { Axonal } \\
\text { sprouts }\end{array}$ & $\begin{array}{l}\text { Sprouts } \\
<200 \\
\text { lesion }\end{array}$ & $\begin{array}{l}\text { Sprouts } \\
>200 \\
\mu \mathrm{m} \text { from } \\
\text { lesion }\end{array}$ \\
\hline Linear rostrocaudally & 401 & 154 & 93 & 432 \\
oriented sprouts & $(65)^{a}$ & $(69)$ & $(33)$ & $(77)$ \\
All other sprouts & 219 & 69 & 189 & 128 \\
& $(35)$ & $(31)$ & $(67)$ & $(23)$ \\
Total sprouts & 620 & 223 & 282 & 560 \\
& $(100)$ & $(100)$ & $(100)$ & $(100)$
\end{tabular}

$\overline{\text { A total of } 842 \text { sprouts evoked by either close or intermediate axotomy of } \mathrm{ABCs}}$ as examined to see if morphology correlated with either their site of origin (dendritic or axonal) or proximity to the lesion site. The criteria used to distinguish "linear, rostrocaudally oriented" sprouts from others are described in Materials and Methods. Although there was no apparent correlation between the site of sprout origin and sprout trajectory ( $p>0.20, \chi^{2}$ test), there is a clear tendency for sprouts in the area of the lesion to follow more tortuous courses and be less influenced by the rostrocaudal axis whether they originate from the axon stump or the dendrites $\left(p \ll 0.005, \chi^{2}\right.$ test $)$.

${ }^{a}$ Values in parentheses represent percentages.

of the primary, secondary, and tertiary dendritic trunks, with finer branches frequently disappearing entirely. This process is progressive, as the dendrites of cells examined at very late times postaxotomy ( 6 months or more) showed an outright loss of many secondary and tertiary branches accompanied by a re. duction in the extent of the dendritic field. This reduction is clearly evident in a cross-sectional view of retracted cells (Fig. $7 B$ ) whose dendrites no longer reach the ventral margin of the brain.

The somata of axotomized cells also exhibited changes during dendritic retraction, developing a swollen, rounded appearance in comparison with control cells. The combination of narrowed lateral dendrites and swollen somata gave retracted cells a markedly different profile in cross section from that of normal $\mathrm{ABCs}$ (Fig. 7).

Retraction of neuritic sprouts was similar to dendritic retraction in that a marked reduction in sprout diameter and length occurred by several months postaxotomy. The mean total extent of sprouting reached a maximum by $100 \mathrm{~d}$ after close axotomy and declined significantly thereafter (Fig. 8). Unlike dendrites, the mean number of sprouts present per cell did not decrease with retraction (18.2 sprouts/cell at $100 \mathrm{~d}$ versus 20.1 sprouts/ cell at $180 \mathrm{~d}$ postaxotomy); the reduction in the total length of sprouting per cell $(408 \mu \mathrm{m} /$ cell at $100 \mathrm{~d}$ versus $191 \mu \mathrm{m} / \mathrm{cell}$ at $180 \mathrm{~d})$ was achieved entirely by a shortening of the average sprout. The morphology of sprout tips was also affected by retraction. Amorphous swellings at the sprout tips were more prevalent at late times postaxotomy, occurring in $44 \%$ of all sprouts before $115 \mathrm{~d}$ versus $70 \%$ of all sprouts after $150 \mathrm{~d}(p<$ $0.01 ; \chi^{2}$ test).

Intact $\mathrm{ABCs}$ contralateral to the axotomized cells were used as controls. No sign of either sprouting or retraction was ever seen in any of 24 such cells examined. 

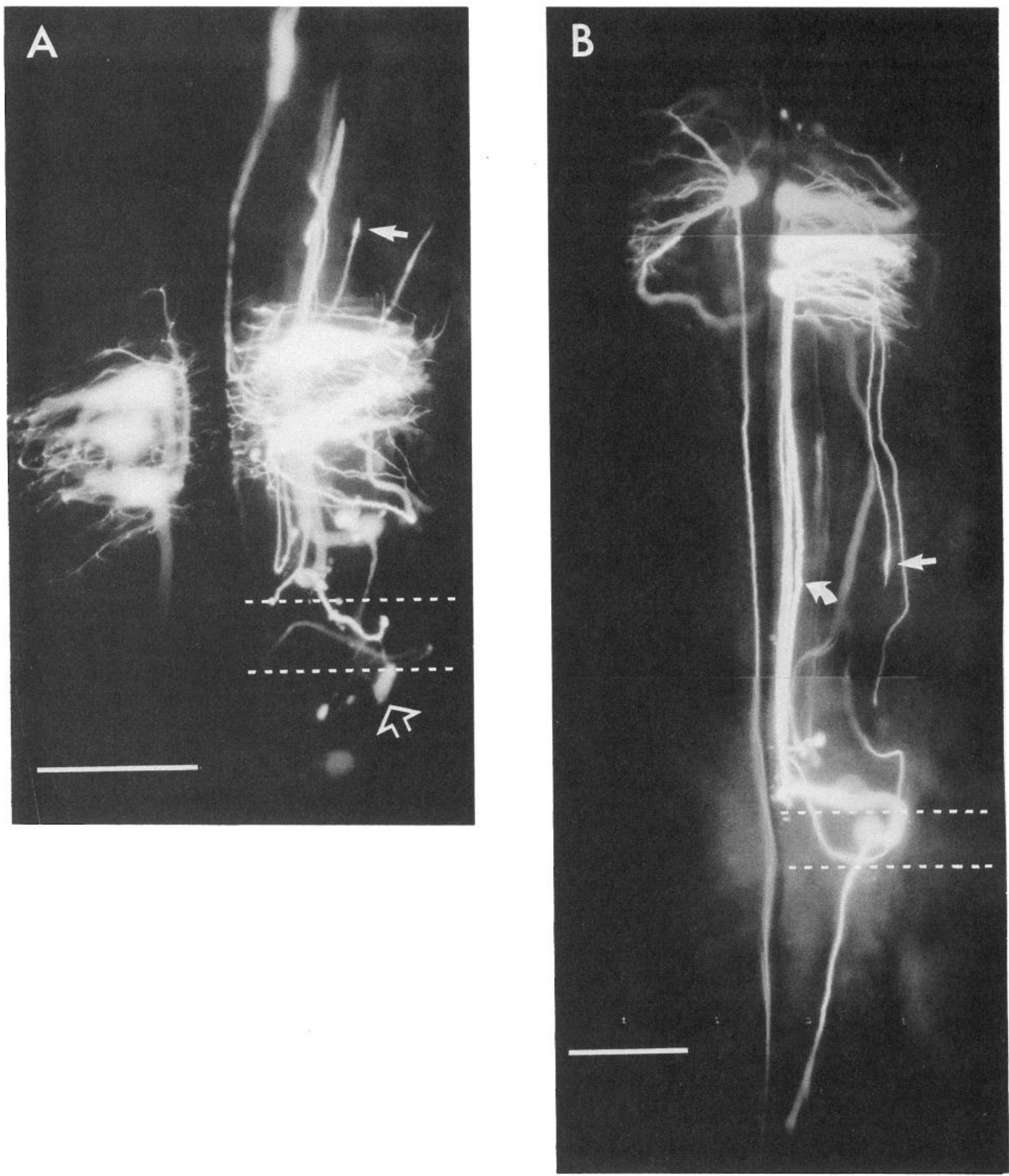

Figure 5. Sprout morphology and trajectories following close and intermediate axotomy produced by hemisection of the hindbrain. Control cells are on the left in each case. Lucifer yellow fills of ABCs $50 \mathrm{~d}$ after close $(A)$ and intermediate $(B)$ axotomy exhibit linear, axially oriented sprouts originating from both dendrites and axon. Most of these sprouts thus resemble $\mathrm{ABC}$ axons: in $B$, compare dendritic sprout (straight solid arrow) with axon stump (curved solid arrow). Disruption of this pattern occurs only near lesion sites (located between dashed lines). Swollen sprout tips near the lesion site usually have amorphous bloblike shapes $(A$, hollow arrow), while swellings on sprout tips more distant from the lesion tend to have "spindle" shapes oriented along the rostrocaudal axis (straight solid arrows). Note that all axonal sprouts following intermediate axotomy (B) originate at the lesion site and not from the shaft of the axon away from the lesion. Control cells contralateral to the lesion sites do not sprout. Although the control cell in $B$ has an unusually dispersed dendritic tree along the rostrocaudal axis (see Fig. 2), its dendrites are clearly different from dendritic sprouts owing to the axonlike morphology and trajectories of the latter. Scale bars, $200 \mu \mathrm{m}$. 


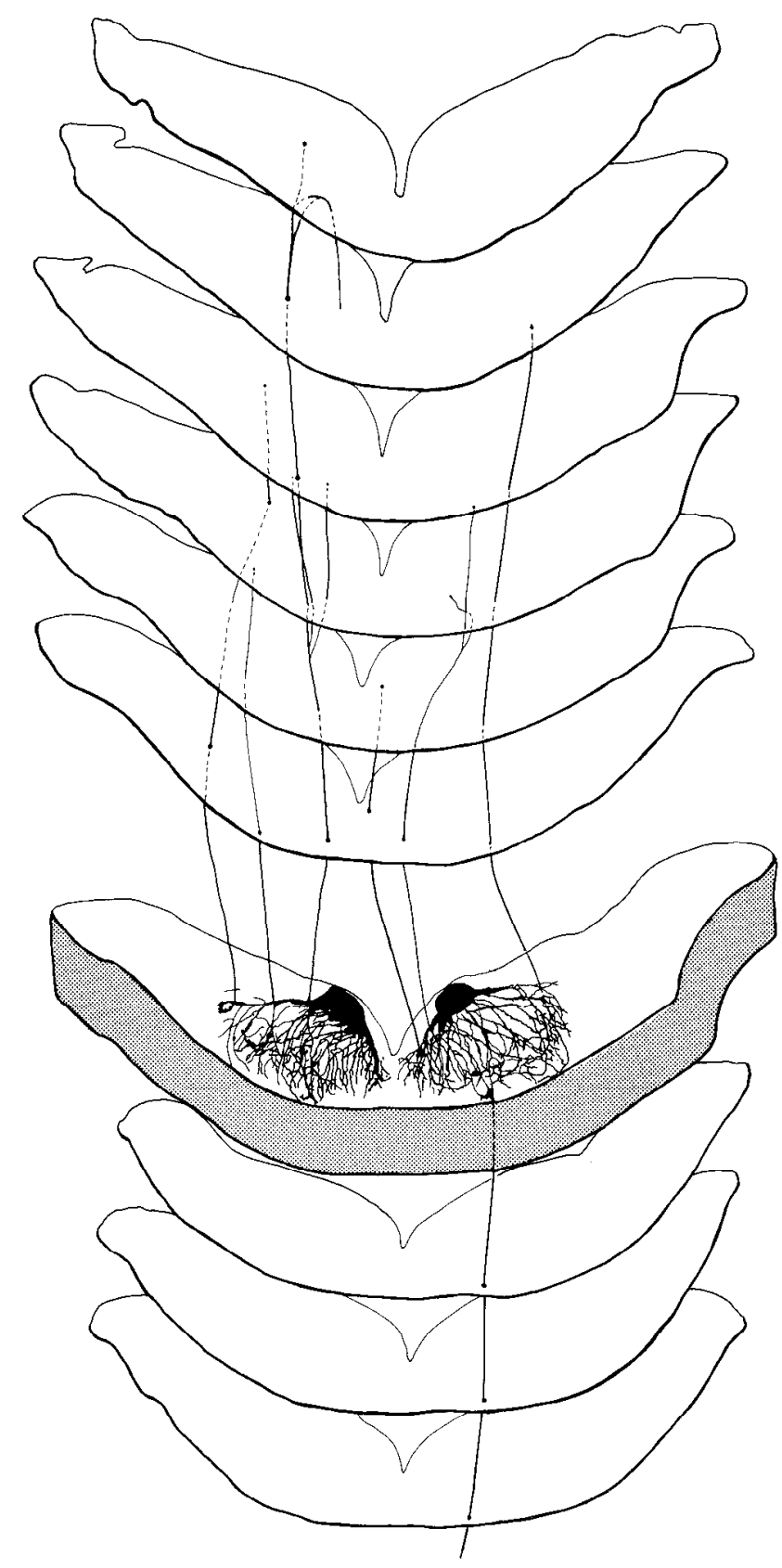

Figure 6. Set of reconstructed cross sections of $2 \mathrm{ABCs}$ subjected to close axotomy $86 \mathrm{~d}$ previously, showing the paths followed by dendritic sprouts within the hindbrain. Several linear, unbranched sprouts can be seen extending both rostrally and caudally. The section containing the somata and dendrites is $100 \mu \mathrm{m}$ thick and was serially reconstructed from $10 \mu \mathrm{m}$ sections. All of the others represent single $10 \mu \mathrm{m}$ sections spaced $100 \mu \mathrm{m}$ apart (except for the one immediately rostral to the soma and dendrites, which is $150 \mu \mathrm{m}$ rostral to the "soma" section). Most of the sprouts can be seen growing in the "basal plate" region of the brain near the ventral margin, where they maintain a constant position with respect to both mediolateral and dorsoventral axes.

\section{Effect of distant axotomy on the response to a subsequent close axotomy}

The time course of both sprouting and retraction of $\mathrm{ABCs}$ subjected to close axotomy $30 \mathrm{~d}$ after a "conditioning" distant axotomy was distinctly different from that seen after close axotomy alone. A significant amount of sprouting beyond the

\begin{tabular}{|c|c|c|c|c|c|c|}
\hline \multirow{2}{*}{$\begin{array}{l}\text { Sprout } \\
\text { orientation } \\
\text { (last } \\
100 \mu \mathrm{m})\end{array}$} & \multicolumn{5}{|c|}{ Close axotomy } & \multirow{2}{*}{$\begin{array}{l}\text { Inter- } \\
\text { mediate } \\
\text { axotomy } \\
(50 \mathrm{~d})\end{array}$} \\
\hline & $15-45 \mathrm{~d}$ & $50-80 \mathrm{~d}$ & $\begin{array}{l}90- \\
120 \mathrm{~d}\end{array}$ & $120+d$ & Total & \\
\hline $\begin{array}{l}\text { Rostral } \\
\text { sprouts }\end{array}$ & $\begin{array}{c}18 \\
(44)^{a}\end{array}$ & $\begin{array}{c}86 \\
(42)\end{array}$ & $\begin{array}{l}143 \\
(38)\end{array}$ & $\begin{array}{c}67 \\
(48)\end{array}$ & $\begin{array}{l}314 \\
(40)\end{array}$ & $\begin{array}{l}120 \\
(35)\end{array}$ \\
\hline $\begin{array}{l}\text { Caudal } \\
\text { sprouts }\end{array}$ & $\begin{array}{c}9 \\
(22)\end{array}$ & $\begin{array}{l}71 \\
(35)\end{array}$ & $\begin{array}{l}125 \\
(34)\end{array}$ & $\begin{array}{c}44 \\
(31)\end{array}$ & $\begin{array}{l}249 \\
(33)\end{array}$ & $\begin{array}{l}112 \\
(33)\end{array}$ \\
\hline $\begin{array}{l}\text { Lateral } \\
\text { sprouts }\end{array}$ & $\begin{array}{c}14 \\
(34)\end{array}$ & $\begin{array}{c}47 \\
(23)\end{array}$ & $\begin{array}{l}104 \\
(28)\end{array}$ & $\begin{array}{c}29 \\
(21)\end{array}$ & $\begin{array}{l}194 \\
(27)\end{array}$ & $\begin{array}{l}109 \\
(32)\end{array}$ \\
\hline $\begin{array}{l}\text { Total } \\
\text { sprouts }\end{array}$ & $\begin{array}{c}41 \\
(100)\end{array}$ & $\begin{array}{c}204 \\
(100)\end{array}$ & $\begin{array}{c}372 \\
(100)\end{array}$ & $\begin{array}{c}140 \\
(100)\end{array}$ & $\begin{array}{c}757 \\
(100)\end{array}$ & $\begin{array}{c}341 \\
(100)\end{array}$ \\
\hline
\end{tabular}

The orientation of sprout tips (the terminal $100 \mu \mathrm{m}$ of both dendritic and axonal sprouts) was examined at various times following close axotomy and at $50 \mathrm{~d}$ following intermediate axotomy. No significant changes developed over time in the percentage of sprout tips oriented rostrally, caudally, or laterally following close axotomy $\left(p>0.25, \chi^{2}\right.$ test). In particular, there is no indication that initially rostrally growing sprouts reorient to grow caudally towards normal ABC postsynaptic targets.

${ }^{a}$ Values in parentheses represent percentages.

dendritic limit was visible in most conditioned cells by $5 \mathrm{~d}$ after close axotomy (Fig. 9). By contrast, neuritic sprouting outside of the dendritic field was not seen until at least 10-15 d after close axotomy of $\mathrm{ABCs}$ that did not receive a conditioning lesion. By 15-25 d after close axotomy, significantly more dendritic sprouting was visible in conditioned cells than in cells subjected to close axotomy alone $(p<0.03$, Mann-Whitney $U$ test). This increased total amount of dendritic sprouting in conditioned cells in the first few weeks following close axotomy appears to be mainly due to a more rapid onset of sprouting rather than to an increased rate of sprouting (Fig. 9). The morphology of dendritic sprouts was not affected by a conditioning distant axotomy $30 \mathrm{~d}$ before close axotomy.

Another effect of a conditioning distant axotomy on the response to close axotomy was the relatively early onset of retraction in conditioned cells. By $25 \mathrm{~d}$ after reaxotomy, signs of retraction began to appear in the dendrites of some conditioned cells. By $40 \mathrm{~d}$ after reaxotomy ( $70 \mathrm{~d}$ after distant axotomy), the dendrites of most conditioned cells had retracted markedly, and the total amount of dendritic sprouting was significantly less than at $50 \mathrm{~d}$ after close axotomy alone (Fig. 9). A second lesion thus accelerated the onset of retraction relative to the time of the conditioning lesion. Significantly more reaxotomized cells showed dendritic retraction between 50 and $100 \mathrm{~d}$ after the first lesion than did cells subjected to either close or distant axotomy alone ( $p<0.05, \chi^{2}$ test). Similarly, the extent of dendritic sprouting in conditioned cells reached a maximum by $25 \mathrm{~d}$ after reaxotomy ( $55 \mathrm{~d}$ after the conditioning lesion); sprouting from cells subjected to close axotomy alone did not peak until between 80 and $110 \mathrm{~d}$ postaxotomy (Fig. 8).

\section{Discussion}

In this study, we have shown that identified neurons (ABCs) in the lamprey hindbrain respond to axotomy by generating neuritic sprouts from either the cut end of the axon stump or from the dendritic tips, depending on the site of axotomy. Sprouts begin to retract by 3 months postaxotomy, at which time there are also major changes in the dendritic tree. Sprouting and retraction were never seen in intact $\mathrm{ABCs}$, even following extensive injury to adjacent areas of the brain. Both sprouting and 

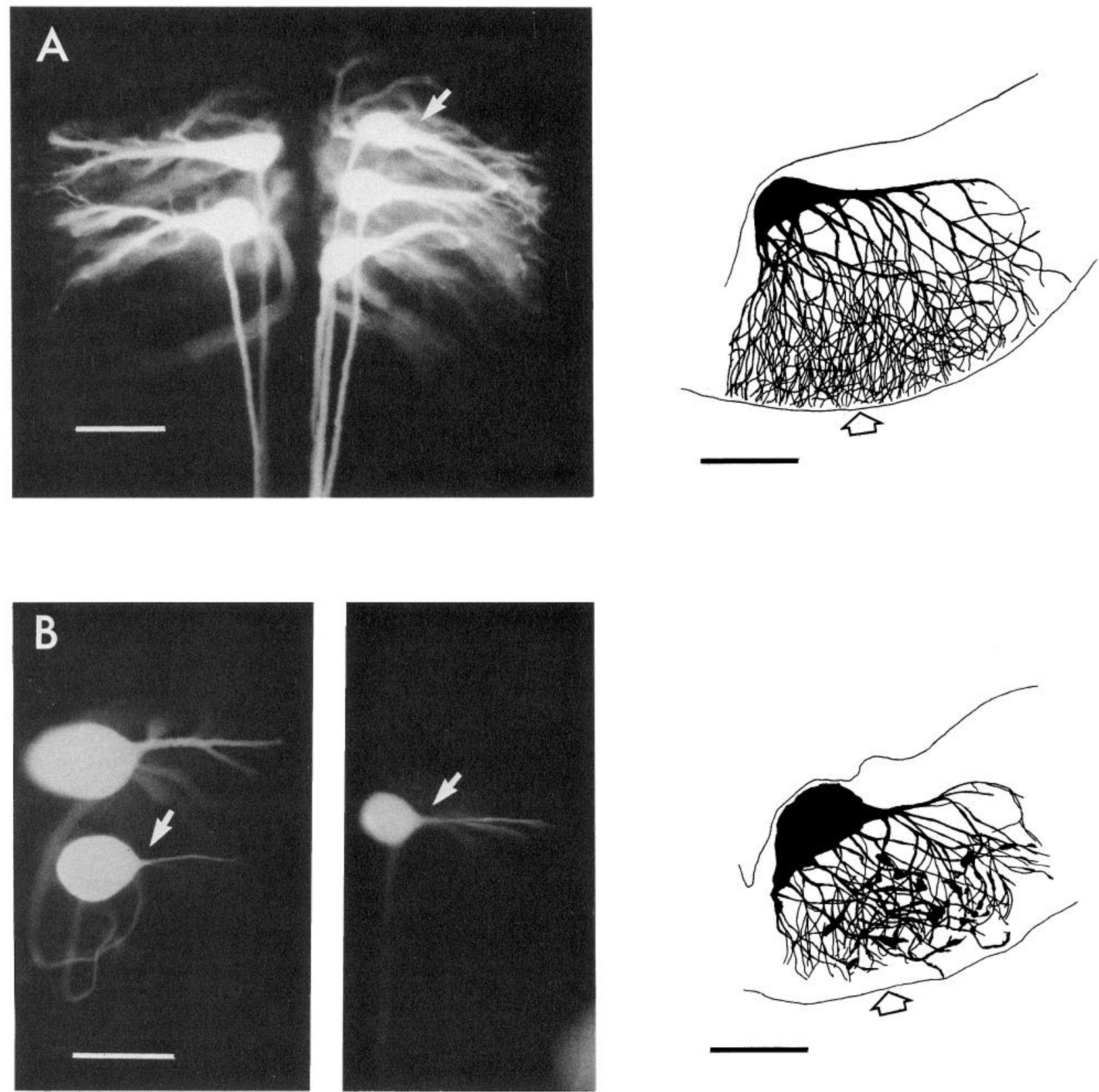

Figure 7. Comparison of normal and retracted ABCs. A, Intact ABCs filled with Lucifer yellow viewed dorsally in whole mount (photo, left) and in cross section (tracing, right). Note the tapered junction between the main lateral dendrite and the soma (solid arrow) and the dense pattern of fine dendritic branches extending to the ventral margin of the brain (hollow arrow). B. Whole mounts of ABCs showing dendritic retraction at 181 $\mathrm{d}$ following close axotomy (photo, left), and in another preparation $105 \mathrm{~d}$ following distant axotomy (photo, center). A cross-sectional reconstruction of a cell $220 \mathrm{~d}$ following close axotomy is shown at right. Compare "ball and stick" profile of soma and main lateral dendrite (solid arrows) with tapered profile of intact cells. Note also the swollen soma and the reduced diameter, complexity, and extent of retracted dendrites compared with the intact cells. Note that the dendrites of the axotomized cell have retracted from the ventral margin of the brain (hollow arrow) and show a number of swollen tips. Scale bars, $100 \mu \mathrm{m}$.

retraction thus appear to require axotomy; they are not responses to extrinsic factors associated with trauma such as substances released by adjacent injured cells or hormonal changes induced by stress.

\section{Sprout distribution after close and intermediate axotomy}

Close and intermediate axotomy evoked roughly the same total amount of neuritic sprouting by $50 \mathrm{~d}$ postaxotomy in lamprey ABCs. However, the distribution of sprouting between dendritic and axonal compartments was quite different. Intermediate ax- otomy evoked mostly axonal sprouting, while close axotomy evoked mostly dendritic sprouting. A similar reciprocal relationship between the amount of dendritic and axonal sprouting evoked by axotomy has also been reported by Roederer and Cohen (1983) in an identified interneuron in the cricket CNS. Both of these results may be viewed as an extension of the principle of "conservation of total axonal arborization" that has been proposed to explain plastic rearrangements that occur following lesions to the olfactory tract (Devor, 1975) and superior colliculus (Schneider, 1973) of neonatal hamsters. It was found 

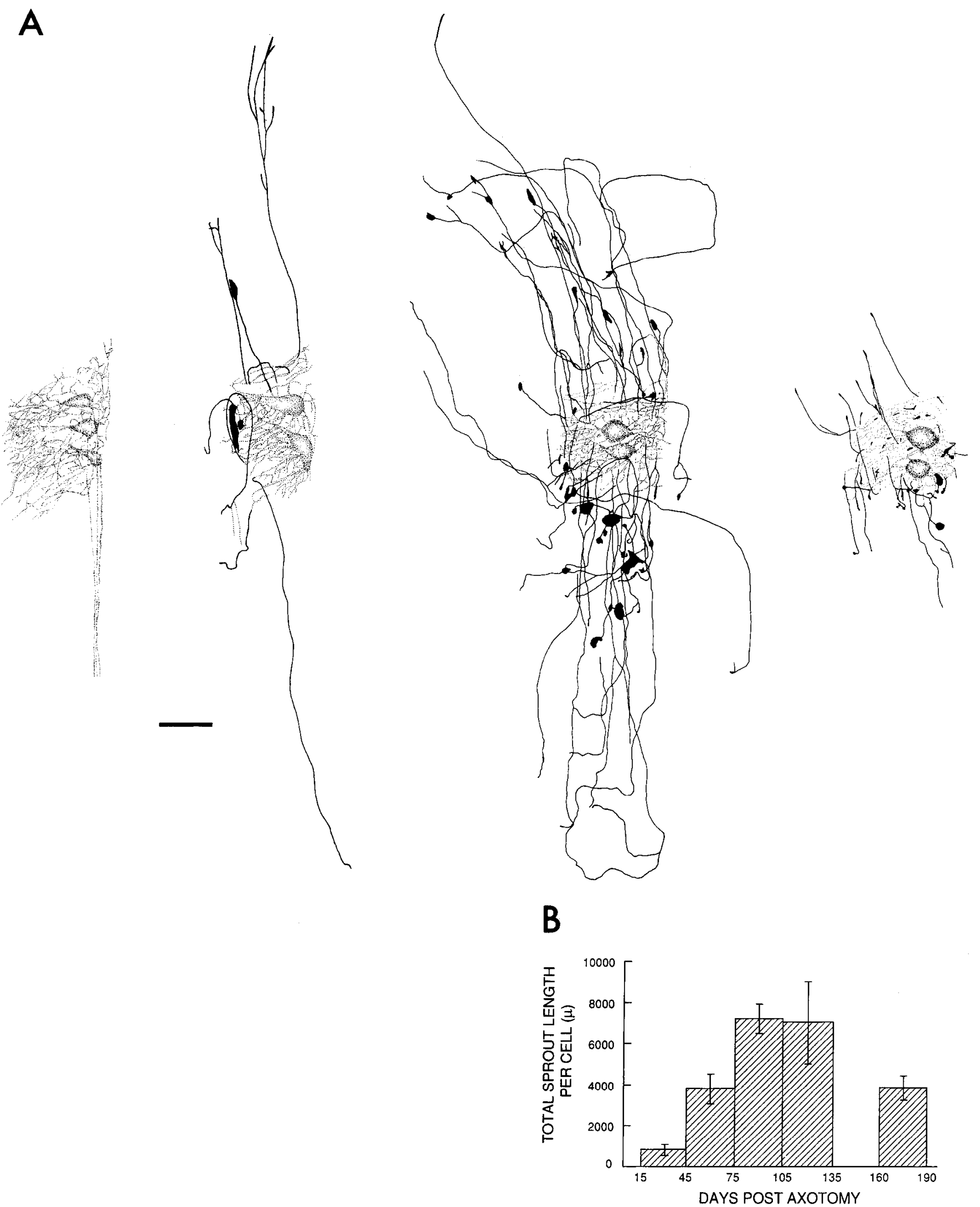

Figure 8. Neuritic sprouting and retraction in response to close axotomy. A, Tracings of intact (extreme left) and axotomized ABCs at successively longer times after axotomy (left center, $62 \mathrm{~d}$; right center, $113 \mathrm{~d}$; extreme right, $181 \mathrm{~d}$ ). Processes in solid black are sprouts; stipple denotes dendritic tree and soma. Note the initial increase in number and length of sprouts with time, followed by retraction. Scale bar, $100 \mu \mathrm{m}$. $B$, Graph of total sprout length per cell versus time (days postaxotomy). Bars indicate mean values $( \pm$ SE) for total sprout length (ordinate) of the cohort being studied (abscissa). Each of the bars was significantly different from its neighbors $(p<0.05$, Mann-Whitney $U$ test) except for the 2 center bars. $N=16$ cells ( $15-45$ d), 22 cells ( $45-75$ d), 18 cells ( $75-105$ d), 16 cells (105-135 d), and 11 cells (160-190 d). 


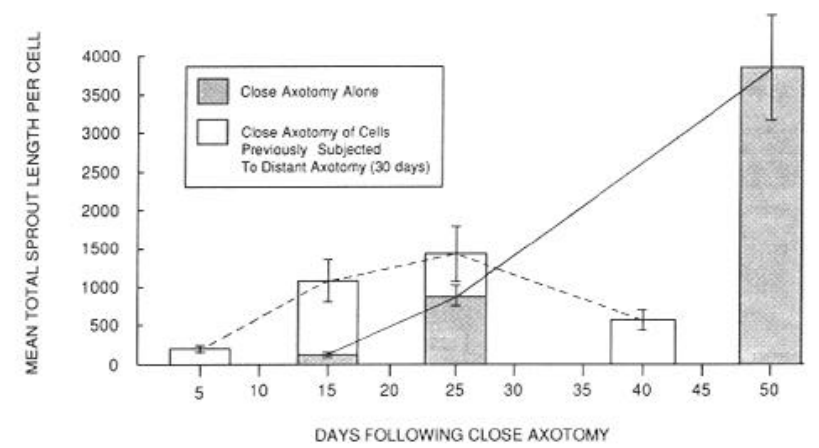

Figure 9. Effect of a conditioning distant axotomy on the time course of sprouting following close axotomy. Graph of the mean total sprout length per cell ( \pm SE) of ABCs subjected to a "conditioning" distant axotomy 1 month before reaxotomy close to the soma. The time course of dendritic sprouting following the second (close) axotomy is given by the open bars connected by the dashed line. The shaded bars connected by the solid line denote the mean total amounts of sprouting per cell following close axotomy alone. Note the early onset of both sprouting and retraction in conditioned cells compared with cells subjected to close axotomy alone. The amount of sprouting from conditioned cells is significantly greater than from control cells $15 \mathrm{~d}$ following close axotomy ( $p<0.01$, Mann-Whitney $U$ test). Sprouting from conditioned cells by $40 \mathrm{~d}$ after reaxotomy was significantly less than that of control cells $50 \mathrm{~d}$ after close axotomy alone ( $p<0.01$, Mann-Whitney $U$ test).

in these systems that, if a population of axons is deprived of some of its terminal arborizations, other parts of the arborizations become denser and expand into foreign territory, leaving the total extent of the arborizations close to what they would have been normally. Conversely, if these axons expand portions of their arborizations into adjacent denervated regions, other parts of their arborizations become stunted. Thus, there appears to be an intrinsic mechanism maintaining the total extent of arborization that compensates for changes imposed from without. A similar mechanism controls the distribution of sprouting within axotomized lamprey ABCs. Here, the amount of growth (the summed length of individual sprouts) arising from a given compartment of the cell depends upon the amount of growth occurring elsewhere within the same cell. The reciprocal relationship between the amount of dendritic and axonal sprouting seen by $50 \mathrm{~d}$ postlesion (Table 1) suggests that axotomy evokes a limited amount of sprouting from ABCs regardless of the distribution of these sprouts within the cell.

We found that the mean length of dendritic sprouts (i.e., the ratio of the total length of all dendritic sprouts to the number of dendritic sprout tips) was not affected by changing the axotomy site. Almost all of the difference between the amounts of dendritic sprouting evoked by close versus intermediate axotomy was due to the 3 -fold difference in the number of sprouts present. The cell thus appears to control the total amount of dendritic sprouting by regulating the number of growth cones that are initiated in the dendrites rather than controlling the rate at which individual growth cones advance. This in turn suggests that growth cones are relatively autonomous once they have been established and that they advance at their own preferred rate so long as the cell produces the materials necessary for sprout elongation. This hypothesis is consistent with the results of studies in culture systems that suggest neuritic growth cones possess a high degree of independence from the parent cell and that their rate of advance is often determined by interactions with the local environment (Letourneau 1975, 1979; Campenot, 1982). Growth cones have been shown to advance and respond to local cues independently of other growth cones belonging to the same cell (Haydon et al., 1984), and even after they have been severed from their parent cell bodies.

The idea that $\mathrm{ABC}$ neuritic growth cones are autonomous units growing at rates determined by their environment is also supported by the observation that axonal sprouts examined 50 d postaxotomy had the same mean length as dendritic sprouts examined at the same time. This was true despite a major difference in the nature of the sites from which dendritic and axonal sprouts originate. Dendritic sprouts grew from a wide choice of sites and rarely branched, whereas axonal sprouts grew only from a restricted region near the end of the axon stump. The axonal growth usually emerged as 1 or 2 thick sprouts that then branched several times, eventually reaching the same ratio between the number of growth cones and total sprout length as was seen in the dendritic sprouts. It is tempting to suppose that the growth pattern of axonal sprouts is due to the inability of the first few growth cones to incorporate the large amount of material being funnelled into them from the axon stump. The sprouts respond to this unstable situation by branching until the total amount of growth is divided among enough growth cones to permit each sprout to elongate at its own preferred rate.

\section{Factors controlling sprout trajectories and morphology}

The paths taken by both dendritic and axonal sprouts exhibited several common features. (1) Sprouts tended to have linear, axial trajectories except in regions near the lesion site, where they followed tortuous paths (Table 2). (2) Sprouts usually grew within the basal plate in the vicinity of the motor columns, where they maintained a constant depth within the brain. (3) Although sprouts tended to be axially aligned, no preference for caudal over rostral growth (or vice versa) was observed. (4) The morphology of sprout tips varied with proximity to the lesion site; elongated, spindle-shaped tips predominated in regions distant from the lesion, while amorphous or bleb-shaped tips were more frequent at or near the lesion site.

These observations suggest that dendritic and axonal sprouts do not possess intrinsic features of gross morphology that are determined by their sites of origin. They also indicate that the external environment encountered by both dendritic and axonal sprouts plays a significant role in determining sprout trajectory. Sprout trajectories may be influenced by 2 major environmental features present in the hindbrain: (1) axially oriented axons in the motor columns of the ventral hindbrain near the sites of emergence of both dendritic and axonal sprouts and (2) disrupted tissue near the scalpel lesion. The axial orientation and simple growth cones of sprouts in areas distant from the lesion suggest that these sprouts may be fasciculating with axially oriented axon tracts. Recent studies have shown that fasciculating axons characteristically display simple, elongated growth cones that are similar to the spindle-shaped growth cones described in this study and unlike those of axons facing a variety of pathway choices (Macagno, 1978; Raper et al., 1983; Tosney and Landmesser, 1985; Caudy \& Bentley, 1986). It is also possible that axially oriented sprouts are growing down glial "tunnels" left by degenerating axons. Such tunnels are known to form after spinal cord section in the lamprey (Roederer et al., 1983). Glial tunnels may also contribute to fiber guidance in the developing CNS (Singer et al., 1979; Krayanek and Goldberg, 1981). In either case, our results indicate that the linear, axial trajectories of most sprouts are probably the result of sprout interactions with local environmental cues rather than an intrinsic preference 
for linear, axial growth expressed independently of the environment. This point is illustrated by initially linear sprouts that assume chaotic trajectories and exhibit amorphous growth cones at the point where they grow through the lesion site. The change in trajectories of these sprouts presumably reflects the disruption of environmental guidance cues resulting from the disorganized tissue regrowth that occurs at lesion sites in the lamprey CNS (Wood and Cohen, 1981).

Although a large majority of sprouts outside of the immediate vicinity of the lesion grew along the rostrocaudal axis, there was no preference for rostral over caudal growth or vice versa. This suggests either that sprouts do not respond to polarity cues directing them specifically towards normal $\mathrm{ABC}$ postsynaptic targets in the spinal cord or that such cues do not exist in the first place. These results contrast with those obtained by Yin et al. (1984) and Mackler et al. (1986), who axotomized giant interneurons in the caudal spinal cord of larval lampreys at points close to their somata. They observed both axonal and dendritic sprouts similar to those described in the present study. However, they found that sprouts from all sites of origin grew in a preferred direction (rostrally in the contralateral spinal cord) towards their normal postsynaptic targets in the rostral cord and hindbrain. Furthermore, axotomized Muller axons in the spinal cord (presumably including those of $\mathrm{ABCs}$ ) also demonstrated a strong preference for caudal growth in the "correct" direction. The differences between our results and theirs suggest that there may be important differences between the environmental guidance cues recognized by $\mathrm{ABC}$ sprouts in the caudal spinal cord and the hindbrain.

\section{Nature of neuritic sprouts}

We have shown that axotomy of ABCs can elicit sprouting from dendritic tips as well as from the axon stump. This raises the question of whether dendritic sprouts are intrinsically dendritelike or axonlike in nature. This issue is of particular interest in light of the major morphological and functional differences between most axons and dendrites (Peters et al., 1976) and the fundamental role that their differences must play in neuronal behavior. Axotomy close to the soma might cause dendritic sprouting in one of the following ways. (1) Dendritic and axonal sprouting might be controlled by entirely separate programs. Thus, close axotomy might signal the cell to reactivate the developmental programs that induced and controlled the growth of the original dendritic tree during development, while distant axotomy reactivates only those programs responsible for axonal growth. In this case, sprouts originating from dendrites would be intrinsically dendritic in nature. (2) Alternatively, close axotomy might induce axonal regeneration in the same way as docs distant axotomy, with sprouting being shunted into the dendrites either because the axon stump has been damaged by close axotomy and has thus become a less attractive location for new growth (Roederer and Cohen, 1983) or because close axotomy has in some way caused the dendrites to become more attractive sites for sprout initiation. In this case, dendritic sprouts would be regenerating "axons" sprouting from ectopic locations in the cell.

Several of our results suggest that both dendritic and axonal sprouts resemble axons rather than dendrites and are controlled by a common program set in motion by axotomy, thereby supporting the second possibility. First, dendritic and axonal sprouts are similar in their gross morphology and trajectories; they resemble axons and differ from dendrites in their extent, direction of growth, and branching patterns. Furthermore, one effect of distant axotomy on the sprouting induced by a subsequent close axotomy is to accelerate the onset of dendritic sprouting normally seen following close axotomy (Fig. 9). This is similar to the "conditioning lesion effect" seen in mammalian peripheral nerves, where the rate of axonal regeneration is accelerated after a second lesion relative to that seen after a single axotomy (McQuarrie et al., 1977). The simplest explanation of this phenomenon in ABCs is that the cell metabolism is already primed for axonal regeneration by the initial distant axotomy. Thus, the materials needed for axonal regeneration can be immediately shunted into the dendrites once they are made more receptive to membrane insertion following close axotomy. Finally, the reciprocal relationship seen between the amount of dendritic and axonal sprouting after close and intermediate axotomy also argues in favor of a common mechanism controlling all axotomy-induced sprouting regardless of its site of origin.

We have presented evidence elsewhere further supporting the hypothesis that dendritic sprouts are ectopically regenerating axons. Growth cones of both dendritic and axonal sprouts occasionally display a distinctive palmate shape when they reach the ventral margin of the brain (Cohen and Hall, 1986). This configuration is characteristic of growth cones engaged in highaffinity interactions with their substrate (Letourneau, 1975, 1979). This suggests that sprouts may specifically recognize surfaces that are thought to guide outgrowing axons during embryogenesis in a number of vertebrate species (Constantine-Paton and Capranica, 1976; Katz and Lasek, 1982; Katz, 1984; Silver and Rutishauser, 1984). Most importantly, we have also found that the ultrastructure of dendritic sprouts is very similar to that of axons and unlike that of dendrites (Hall et al., 1987). These results, considered en toto, suggest that dendritic sprouts are intrinsically axonal in nature and may be actively following guidance cues appropriate for axons. The axonlike gross morphology and trajectories of these sprouts may therefore be due to intrinsic determinants as well as to passive channelling by physical features in the environment.

\section{Retraction of dendrites and neuritic sprouts}

This study has shown that 2 events are set in motion by axotomy of lamprey ABCs: (1) neuritic sprouting from the axon stump and/or dendrites and (2) the subsequent retraction of both the sprouts and the dendritic tree. Each of these phenomena has been reported separately in various neuron types following axotomy. Profuse sprouting from the proximal axon stump is common following axotomy in most neuronal types with the exception of mammalian central neurons, which do not sprout extensively except under extraordinary circumstances (David and $\Lambda$ guayo, 1981; Benfey and Aguayo, 1982). Dendritic sprouting following axotomy close to the soma has been observed in invertebrates (Murphey and Kater, 1980; Roederer and Cohen, 1983) as well as in the lamprey. Dendritic retraction after axotomy has been recorded in vertebrate motoneurons (Cerf and Chacko, 1958; Sumner and Watson, 1971), where it has been shown that such retraction results from the disconnection of the axotomized neuron from its postsynaptic contacts (Sumner and Watson, 1971). However, the present paper is the first instance to our knowledge in which both dendritic sprouting and retraction have been observed in a single identified cell.

It is not clear which of the various consequences of axotomy (i.e., loss of axoplasm, disconnection from postsynaptic contacts, etc.) are responsible for sprouting and retraction in lam- 
prey ABCs. Sprouting and retraction appear to be separate phenomena which follow independent timetables rather than 2 aspects of a single phenomenon that must nccur in a fixed sequence. Retraction affects the dendrites of axotomized cells in the same way regardless of whether or not dendritic sprouting has occurred. Retraction thus appears to be "superimposed" on sprouting that has already occurred rather than being simply a reversal of sprouting. Reaxotomy of $\mathrm{ABCs}$ accelerates the onset of retraction so that it occurs much earlier after the initial axotomy than after close axotomy alone. Consequently, in reaxotomized cells retraction occurs much sooner after the initiation of sprouting than it does in cells with only one lesion. This indicates that sprouting and retraction are not "phase locked" with respect to one another. Furthermore, dendritic sprouting has been observed in some $\mathrm{ABCs}$ that were reaxotomized close to the soma $150 \mathrm{~d}$ after a conditioning distant axotomy, suggesting that sprouting can occur in ABCs that have alrcady undergone dendritic retraction (Hall, 1985).

It is uncertain whether dendritic retraction is a symptom of a long-term, irreversible decline leading eventually to deterioration and cell death, and if so, whether a prolonged period of deterioration is an inevitable consequence of axotomy. We have observed some loss of $\mathrm{ABCs}$ in lampreys examined at very long times $(300+$ d) postaxolomy, suggesting that some cell death does eventually occur among axotomized cells (G. Hall, unpublished observation). One obvious possiblity is that the ABCs which reestablish stable postsynaptic contacts following axotomy continue to survive, while those that do not eventually die. Many axotomized ABCs (especially those that do not have sprouts crossing the lesion) probably do not reestablish contact with their normal postsynaptic targets in the spinal cord. It remains to be seen whether reestablishment of synaptic contacts (original or otherwise) plays a role in either the retraction or long-term survival of axotomized ABCs.

In summary, axotomy of lamprey $\mathrm{ABCs}$ results in 2 types of large-scale change in neuronal morphology: (1) neuritic sprouting from the axonal and/or dendritic compartments of the cell and (2) the eventual retraction of both the sprouts and a large proportion of the original dendritic tree. Dendritic and axonal sprouts have similar morphological characteristics and trajectories and appear to be guided by local features in their environment. Furthermore, the total amount of sprouting from the dendrites and axon is not affected by changing the site of axotomy, suggesting that dendritic and axonal sprouts may be identical in all respects except their sites of origin. The various factors that control the distribution of sprouting evoked by injury in lamprey $\mathrm{ABCs}$ are the focus of the accompanying paper (Hall and Cohen, 1988).

\section{References}

Bartlett, W. P., and G. A. Banker (1984) An electron microscopic study of the development of axons and dendrites by hippocampal neurons in culture. I. Cells which develop without intracellular contacts. J. Neurosci. 4: 1944-1953.

Benfey, M., and A. I. Aguayo (1982) Extensive elongation of axons from rat brain into peripheral nerve grafts. Nature 296: 150-152.

Campenot, R. B. (1982) Development of sympathetic neurons in compartmentalized cultures. I. Local control of neurite growth by nerve growth factor. Dev. Biol. 93: 1-15.

Caudy, M., and D. Bentley (1986) Pioneer growth cone morphologies reveal proximal increases in substrate affinity within leg segments of grasshopper embryos. J. Neurosci. 6: 364-379.

Cerf, J. A., and L. W. Chacko (1958) Retrograde reaction in moto- neuron dendrites following ventral root section on the frog. J. Comp. Neurol. 109: 205-216.

Cohen, M. J., and G. F. Hall (1986) The control of neuron shape during development and regeneration. Neurochem. Pathol. 5: 331343.

Constantine-Paton, M., and R. P. Capranica (1976) Axonal guidance of developing optic nerves in the frog. I. Anatomy of the projection from transplanted eye primordia. J. Comp. Neurol. 170: 17-32.

David, S., and A. J. Aguayo (1981) Axonal elongation into peripheral nervous system "bridges" after central nervous system injury in adult rats. Science 214: 931-933.

Devor, M. (1975) Neuroplasticity in the rearrangement of olfactory tract fibers after neonatal transection in hamster. J. Comp. Neurol. I66: 49-72.

Fishman, P. S. (1975) A study of dendritic form in identificd lamprey neurons. Ph.D. dissertation, Yale University.

Hall, G. F. (1985) Morphological plasticity of lamprey central neurons evoked by axonal and dendritic injury. Ph.D. dissertation, Yale University.

Hall, G. F., and M. J. Cohen (1983) Extensive dendritic sprouting induced by close axotomy of central neurons in the lamprey. Science 222: 518-521.

Hall, G. F., and M. J. Cohen (1988) Dendritic amputation redistributes sprouting evoked by axotomy in lamprey central neurons. J. Neurosci. 8: 3598-3606.

Hall, G. F., A. Poulos, and M. J. Cohen (1987) Ultrastructure of dendritic sprouts seen following close axotomy of giant central neurons in the lamprey. Soc. Neurosci. Abstr. 13: 280.12.

Haydon, P. G., D. P. McCobb, and S. B. Kater (1984) Serotonin selectively inhibits growth cone motility and synaptogenesis of specific identified neurons. Science 226: 561-564.

Katz, M. J. (1984) Stereotyped and variable growth of redirected Mauthner axons. Dev. Biol. 104: 199-209.

Katz, M. J., and R. Lasek (1982) Substrate pathways demonstrated by transplanted Mauthner axons. J. Comp. Neurol. 195: 627-641.

Krayanek, S., and S. Goldberg (1981) Oriented extracellular channels and axonal guidance in the embryonic chick retina. Dev. Biol. 84: 41-50.

Letourneau, P. C. (1975) Cell-to-substratum adhesion and guidance of axonal elongation. Dev. Biol. 44: 92-101.

Letourneau, P. C. (1979) Cell substratum adhesion of neurite growth cones, and its role in neurite elongation. Exp. Cell Res. 124: 127138.

Macagno, E. R. (1978) Mechanism for the formation of synaptic projections in the arthropod visual system. Nature 275: 318-320.

Mackler, S. A., H-S. Yin, and M. E. Selzer (1986) Determinants of directional specificity in the regeneration of lamprey spinal axons. J. Neurosci. 6: 1814-1821.

Martin, R. J. (1979) A study of the morhpology of the large reticulospinal neurons of the lamprey ammocoete by intracellular injection of Procion Yellow. Brain Behav. Evol. 16: 1-18.

McQuarrie, I. G., B. Grafstein, and M. D. Gershon (1977) Axonal regeneration in the rat sciatic nerve: Effect of a conditioning lesion and of dbC.AMP. Brain Res. 132: 443-453.

Murphey, A. D., and S. B. Kater (1980) Sprouting and functional regeneration of an identified neuron in Helisoma. Brain Res. 186: 251-272.

Peters, A., S. L. Palay, and H. D. Webster (1976) The fine structure of the nervous system: The neurons and supporting cells. Saunders, Philadelphia.

Raper, J. A., M. J. Bastiani, and C. S. Goodman (1983) Guidance of neuronal growth cones: Selective fasciculation in the grasshopper embryo. Cold Spring Harbor Symp. Quant. Biol. 48: 587-598.

Roederer, E., and M. J. Cohen (1983) Regeneration of an identified central neuron in the cricket. I. Control of sprouting from soma, dendrites, and axon. J. Neurosci. 3: 1835-1847.

Roederer, E., N. H. Goldberg, and M. J. Cohen (1983) Modification of retrograde degeneration in transected spinal axons of the lamprey by applied DC current. J. Neurosci. 3: 153-160.

Rovainen, C. M. (1976) Regeneration of Muller and Mauthner axons after spinal transection in larval lampreys. J. Comp. Neurol. 168: 545-554.

Schacher, S., and E. Proshansky (1983) Neurite regeneration by Aplysia neurons in dissociated cell culture: Modulation by Aplysia hemolymph and the presence of the initial axonal segment. J. Neurosci. 3: 2403-2413. 
Schneider, G. E. (1973) Early lesions of superior colliculus: Factors affecting the formation of abnormal retinal projections. Brain Behav. Evol. 8: 73-109.

Selzer, M. E. (1978) Mechanism of functional recovery and regeneration after spinal cord transection in the larval sea lamprey. J. Physiol. (Lond.) 277: 395-408.

Silver, J., and U. Kutishauser (1984) Guidance of optic axons in vivo by a preformed adhesive pathway on neuroepithelial endfeet. Dev. Biol. 106: 485-499.

Singer, M., R. H. Nordlander, and M. Egar (1979) Axonal guidance during embryogenesis and regeneration in the spinal cord of the newt. The blueprint hypothesis of neuronal pathway patterning. J. Comp. Neurol. 185: 1-22.

Stewart, W. H. (1978) Functional connections between cells as revealed by dye-coupling with a highly fluorescent naphthalimide. Cell 14: 741-759.

Sumner, B. E. H., and W. E. Watson (1971) Retraction and expansion of the dendritic tree of motor neurones of adult rat induced in vivo. Nature 233: 273-275.

Tosney, K. W., and L. T. Landmesser (1985) Growth cone morphology and trajectory in the lumbosacral region of the chick embryo. J. Neurosci. 5: 2345-2358.

Wickelgren, W. O. (1977) Physiological and anatomical characteristics of reticulospinal neurones in lamprey. J. Physiol. (Lond.) 270: 89116.

Wood, M. R., and M. J. Cohen (1979) Synaptic regeneration in identified neurons of the lamprey spinal cord. Science 206: 344-347.

Wood, M. R., and M. J. Cohen (1981) Synaptic regeneration and glial reactions in the transected spinal cord of the lamprey. I. Neurocytol. 10: $57-79$

Yin, H.-S., S. A. Mackler, and M. E. Selzer (1984) Directional specificity in the regeneration of lamprey spinal axons. Science 224:894896. 